\title{
Job Competence of Agricultural Officers in Southern zone of Andhra Pradesh, India
}

\author{
D. V. Kusumalatha* and N. S. Shivalinge Gowda \\ Department of Agricultural Extension, UAS, GKVK, Bengaluru, Karnataka, India \\ *Corresponding author
}

K e y w o r d s
Job competence,
Self-rating,
Superior rating,
Dimensions, Mean
score index

\section{A B S T R A C T}

The present study was conducted to know the Job competence of agricultural officers in the Southern zone of Andhra Pradesh consists of 3 districts viz., Chittoor, Y.S.R. Cuddapah and Nellore. The population of the study consists of 30 agricultural officers working in the department of agriculture in each district. Disproportionate random sampling method was employed for selecting the sample. Thus the total sample size was 90. Ex-post-facto research design was followed. Data was collected through personal interview method and using questionnaires. The findings of the study are the majority of 41.11 per cent of Agricultural Officers belongs to the medium level of job competence whereas 30.00 per cent and 28.89 per cent belongs to high and low category. Concerning self-rating and superior rating majority of $42.22 \%$ and $37.77 \%$ Agricultural officers belonging to the medium category respectively, which shows still there is a greater potential to increase the competency level of the employees. Further, the results also have shown that the judgement, one of the dimensions of job competence was having a high mean score index both in self-rating and superior rating whereas self-development has low mean score index in self-rating and adaptability has low mean score index in superior rating. Which further gives an in-depth analysis of in which areas competency of the employees was lacking so that the department authorities can work on it for further improvement.

\section{Introduction}

Competence is the degree of ability for performing certain kind of tasks. Competencies of an individual underline his performance at work. Draganidis and Mentzas (2006) describe in their article competency as being "a combination of tacit and explicit knowledge, behaviour and skills that gives someone the potential for effectiveness in task performance". Anisha (2012) reported that competency is a set of knowledge, skills and attitudes required to perform a job effectively and efficiently. A Competency is something that describes how a job might be done excellently; a competence only describes what has to be done, not how. Organisations can take advantage of these competencies of an individual in improving their productivity. Raut (2006) found that majority (72.00\%) of 
the AAs themselves and their immediate superiors $(48.08 \%)$ have rated job competency of the AAs as good.

Vijaibabu (2005) in his study onjob competence of agricultural officers found that majority $(66.67 \%)$ of the agricultural officers had medium level of job competence followed by low $(17.65 \%)$ and high (15.68 $\%)$ level of job competence respectively. Solomon (2013) tried to explore the level of competency prevailing among the executives working in the public sector. The results of the study showed that nearly half of the respondents had moderate level of managerial HR and general competencies.

Amit et al., (2014) revealed that majority $(46.88 \%)$ of agricultural officers had high level of job competence while remaining 28.13 and 25.00 per cent had low and medium level of job competence, respectively. The competencies of extension workers need to be continuously developed, without the same an organisation is not likely to achieve its goals.

The findings of the present study give the detailed account on the competency levels of the Agricultural Officers in the Southern zone of Andhra Pradesh. It helps the Agricultural Officers to know where exactly they stand in the organization with respect to their job competence and it would be of immense practical value to the concerned policy makers, professionals as well as administrators and others concerned with Agricultural Departments to evolve and inculcate appropriate Human Resource Management (HRM) approaches in order to create and foster a congenial work atmosphere in the organization.

\section{Materials and Methods}

The study was conducted during 2017-18 in Chittoor, Y.S.R Cuddapah and Nellore districts which falls under southern zone
(NARP) of Andhra Pradesh. By following Expost facto design. $30 \mathrm{AOs}$ from each district were selected for study by applying disproportionate sampling method. Thus, a total sample size of 90 AOs were considered for the study. Job competence is operationally defined as "the extent of possession of adequate abilities/qualities by an agricultural officer in state department of agriculture, which aids him/her in performing his/her tasks". Mean, percentage and standard deviation was employed for analysis.

\section{Results and Discussion}

The Job competence of AOs was measured by using the scale developed by Reddy (1990) with slight modifications. The scale consists of 10 dimensions. Each dimension has 6 statements, thus a total of 60 statements were taken for the study. In the present study selfrating and rating by superiors are measured separately to compare the competence of AOs by themselves and by their next superiors. Overall job competence of Agricultural officers was measured by considering the mean of both self-rating and rating by superiors.

It was observed from table 1 that, two-fifth of the Agricultural Officers (42.22\%) belongs to medium extent of job competence followed by 30.00 per cent and 27.78 per cent high and low extent of competency.

Table 2 shows the job competence ratings given by the next superiors to the Agricultural Officers. It is evident from the investigation that, 37.77 per cent of the agricultural officers belonged to medium extent of job competence whereas, 34.45 per cent and 27.78 per cent belonged to low and high category of job competence.

The findings on the overall job competence of agricultural officers are presented in table 3 . It could be observed from the table that a 
majority of the AOs $(41.11 \%)$ belonged to medium job competence category. The number of agricultural officers belonging to high category and low job competency category were more or less equal $(30.00 \%$ and $28.89 \%$ respectively). The mean job competence core was 199.14 and the standard deviation was 8.32. Based on this the classification of agricultural officers into low, medium and high was made.

The reason for a majority of agricultural officers possessing medium job competence might be due to similar working environment with uniform organisational climate, facilities and resources. Majority of agricultural officers had medium achievement motivation, perceived workload and job experience etc., which might have influenced the job competence of agricultural officers. Lack of professionalism, less training facilities, absence of incentives might be reasons for not having high competence among agricultural officers.

A detailed analysis of job competence of agricultural officers in respect of the ten dimensions of job competence is presented in Figure 1. A cursory look at this figure indicates that the percentage of scores for the areas of Judgement was the highest with respect to both self as well as rating by superiors.

Table.1 Job competence of agricultural officers (Self-rating)

$\mathrm{n}=90$

\begin{tabular}{|c|l|c|c|c|c|}
\hline SI. No. & Extent of job competence & $\begin{array}{c}\text { No. of } \\
\text { respondents }\end{array}$ & Per cent & Mean & S.D. \\
\hline 1. & Low $(<197.84)$ & 25 & 27.78 & 202.14 & 8.61 \\
\hline 2. & Medium $(197.84-206.45)$ & 38 & 42.22 & & \\
\hline 3. & High $(>206.45)$ & 27 & 30.00 & & \\
\hline
\end{tabular}

Table.2 Job Competence of agricultural officers (Rating by Superiors*)

$\mathrm{n}=90$

\begin{tabular}{|c|l|c|c|c|c|}
\hline SI. No. & Extent of job competence & $\begin{array}{c}\text { No. of } \\
\text { respondents }\end{array}$ & Per cent & Mean & S.D. \\
\hline 1. & Low $(<191.75)$ & 31 & 34.45 & & \multirow{2}{*}{196.14} \\
\hline 2. & Medium $(191.75-200.54)$ & 34 & 37.77 & 8.79 \\
\hline 3. & High $(>200.54)$ & 25 & 27.78 & & \\
\hline
\end{tabular}

*- 13 ADAs had rated 90 AOs for Job Competence

Table.3 Overall job competence of agricultural officers

\begin{tabular}{|c|l|c|c|c|c|}
\hline Sl. No. & Extent of job competence & $\begin{array}{c}\text { No. of } \\
\text { respondents }\end{array}$ & Per cent & Mean & S.D. \\
\cline { 1 - 3 } 1. & Low $(<194.98)$ & 26 & 28.89 & 199.14 & 8.32 \\
\hline 2. & Medium $(194.98-203.30)$ & 37 & 41.11 & & \\
\hline 3. & High $(>203.30)$ & 27 & 30.00 & & \\
\hline
\end{tabular}


Fig.1 Job competence of agricultural officers with respect to dimensions

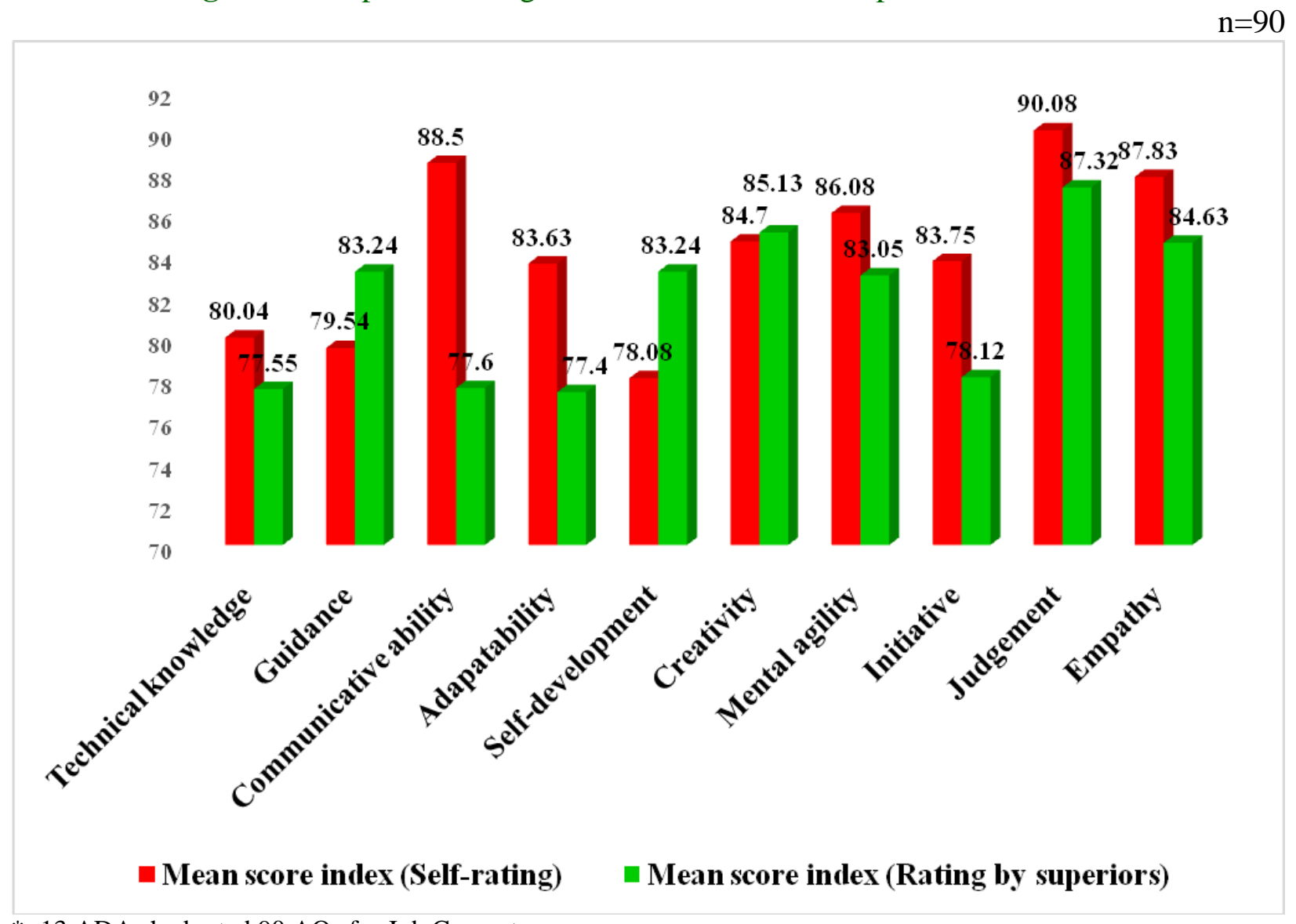

*- 13 ADAs had rated 90 AOs for Job Competence

This was followed by Communicative ability, Empathy, Mental Agility, Creativity, Initiative, Adaptability, Technical Knowledge, Guidance and Self-Development in that order in self-rating whereas, it was followed by creativity, empathy, guidance, self-development, mental agility, initiative, communicative ability, technical knowledge and adaptability in that order with respect to rating by superior.

It is revealed that judgement emerges as the foremost contributing factor for the overall job competence scores of the agricultural officers. But at a second look all the dimensions shows that guidance and selfdevelopment seem to have contributing least towards competence with respect to selfrating. Guidance seems to have least contributing factor as supervision on the subordinates is not up to date. The low level of self-development may be due to monotony in terms of work, lack of promotional avenues and pressures or burdens of work. Adaptability also shows least contributing towards competence with respect to superior rating because superiors feels that still AOs are not adapted to the field situations to give enough suggestions

It can be concluded from the study that the majority of 41.11 per cent Agricultural officers belonged to the medium level of job competence whereas 30.00 per cent and 28.89 per cent belongs to high and low category. Concerning self-rating two-fifth $(42.22 \%)$ of Agricultural officers belonging to the medium category while 37.77 per cent of them belongs 
to the medium category rated by superiors. It shows still there is greater potential to develop the competency levels. Out of 10 dimensions under job competence Judgement is having a high mean score index both in self and superior ratings whereas selfdevelopment and adaptability have low scores in self-rating and superior rating respectively. It gives a further in-depth knowledge of what areas need to be concentrated to solve the problems and increase the job competence of the agricultural officers.

\section{References}

Amit, D., Raj, S., and Jayasree, D., 2014, Job Competence and Job Performance of the Extension Personnel of the Department of Agriculture in Tripura State of North-East India. Int. J. Social
Sci.,3(2), 91-112.

Anisha, N., 2012, Competency Mapping of the Employees. Int. J. Advancements in Research \& Technology, 1(5):1-7.

Draganidis, F., Mentzas, G., 2006, Competency Based Management: A Review of Systems and Approaches. Information Management \& Computer Security.

Raut, R. S., 2006, Job competency, job performance and job satisfaction of agriculture assistants in single window system of agriculture, Ph.D. Thesis (Unpub.), Dr. Punjabrao Deshmukh Krishi Vidyapeeth, Akola.

Solomon, D. M., 2013, Competency mapping- A holistic approach for industries. Indian Journal of Research, 2(3).

\section{How to cite this article:}

Kusumalatha, D. V. and Shivalinge Gowda, N. S. 2020. Job Competence of Agricultural Officers in Southern zone of Andhra Pradesh, India. Int.J.Curr.Microbiol.App.Sci. 9(03): 23942398. doi: https://doi.org/10.20546/ijcmas.2020.903.273 